\title{
PARA HONRA Y GLORIA DE LA ORDEN: LAS PINTURAS DE LAS GENEALOGÍAS DE LAS ÓRDENES RELIGIOSAS EN LOS CONVENTOS QUITEÑOS EN EL BARROCO
}

\author{
FOR THE HONOR AND GLORY OF THE ORDER: \\ THE PAINTINGS OF THE GENEALOGIES OF RELIGIOUS \\ ORDERS IN THE QUITO CONVENTS DURING \\ THE BAROQUE
}

\author{
Ángel Justo Estebaranz \\ Universidad de Sevilla, España \\ ajestebaranz@us.es
}

\begin{abstract}
Las órdenes religiosas masculinas establecidas en Quito encargaron, durante el siglo XVII, grandes pinturas para decorar las cajas de escalera de sus cenobios, que representaban los árboles genealógicos de cada orden. Siguiendo el ejemplo puesto en marcha por los dominicos, tanto agustinos como franciscanos quisieron mostrar a los monjes locales el árbol familiar con sus miembros más destacados. Los mercedarios se sumarían a esta tendencia en la centuria siguiente. Todos ellos se inspiraron para componer estas pinturas tanto en la iconografía del árbol de Jessé como en las estampas flamencas e italianas que circularon por los territorios de Ultramar. En este trabajo se estudian estas pinturas, así como algunas versiones en lienzo y en escultura realizadas a fines del período virreinal.

Palabras clave: Árbol genealógico, órdenes religiosas, Quito, pintura, barroco.
\end{abstract}

During the seventeenth century, the male religious orders established in Quito commissioned large paintings to decorate the stairwells of their monasteries, representing the family trees of each religious order. Following the example started by the Dominicans, both Augustinians and Franciscans wanted to show to the local monks their family trees with their most prominent members. Mercedarians would add to this trend in the next century. They were inspired to compose these paintings both in the iconography of the Tree of Jesse and the Flemish and Italian prints that circulated all over the overseas territories. In this paper we study these paintings as well as some versions in canvas and sculptures made in the late viceregal period.

Keywords: Family tree, religious orders, Quito, painting, baroque 
Durante el siglo XVII se terminan las obras de los grandes conventos masculinos quiteños -San Agustín, San Francisco y Santo Domingo-, y también las de las recoletas franciscana y dominica. La construcción de iglesias y claustros de los principales cenobios capitalinos concluye durante el primer tercio de siglo. Como parte de la decoración de los mismos, se realizan los ciclos pictóricos sobre la vida del fundador de la orden -caso de San Agustín, y quizás incluso de San Francisco ${ }^{1}$-. Junto a las series sobre la vida de los santos y otras que presentaban a religiosos notables dentro de la orden - véase la de cardenales agustinos, los franciscanos de la portería del convento seráfico, etc.-, casi todas las religiones establecidas en Quito abordan en este momento la realización de pinturas que integrasen a sus más sobresalientes miembros. Estas obras se ajustaban a la concepción que tenían los religiosos de su orden como familias con genealogías celestiales que conectaban a los frailes con lo eterno a través del tiempo y del espacio con sus ancestros santos ${ }^{2}$. La estructura de las pinturas, de formato vertical, suele constar de un enorme árbol en cuyo tronco figuran el fundador y a veces la Virgen, más un número variable de santos dispuestos en las ramas. En estas grandes composiciones se podía optar por disponer ordenadas en las diferentes ramas a las congregaciones e institutos que fueron naciendo del tronco original -en el que lógicamente aparecía en lugar destacado el santo fundador-, o bien situar a santos y beatos de la orden según criterios que tenían que ver, entre otros, con la relevancia de cada uno. Y ello lo hacen con una clara intención. Franciscanos y agustinos colocaron en la caja de escalera del claustro principal de su convento quiteño inmensos cuadros realizados al óleo sobre lienzo por autores locales. Por su parte, los dominicos ubicaron una pintura mural en la caja de escalera de la recoleta que habían fundado al sur de la ciudad. El formato se adecuaba a las dimensiones del espacio, y servía como recordatorio a los frailes de su gloriosa genealogía. Para autoafirmarse en tanto que integrantes de la orden en el marco del ámbito quiteño -como desde luego lo harían en tantas otras poblaciones virreinales en las que figuraban estas obras de gran formato-. Junto con esta finalidad, el valor decorativo de las pinturas era fundamental ${ }^{3}$. Unido a todo ello, la idea de

${ }^{1} \mathrm{Si}$ es que efectivamente se llevaron en este momento 54 cuadros de Roma representando la vida del santo, como señalaba Tobar Donoso. Véase TOBAR DONOSO, Julio: La Iglesia, modeladora de la nacionalidad. La Prensa Católica, Quito, 1953, p. 343.

2 Véase MELVIN, Karen: Building Colonial Cities of God: Mendicant Orders and Urban Culture in New Spain. Stanford University Press, Stanford, 2012, p. 77.

${ }_{3}^{3}$ Pérez Morera indica que la conjunción de imagen y texto escrito que se da en estas pinturas de genealogías de la orden hizo de ellas un medio adecuado para la propaganda de las diferentes órdenes religiosas. Asimismo, para este autor, con estas pinturas se propiciaba "tanto una lectura histórica como retórica y mística". Véase PÉREZ MORERA, Jesús: "El árbol genealógico de las órdenes franciscana y dominica en el arte virreinal", Anales del Museo de América, 4, 1996, p. 119. 
situar el cuadro o la pintura mural en la escalera tenía la intención de servir de estímulo diario a los miembros de la comunidad quiteña. Así, ya que los religiosos habrían de subir y bajar la escalera varias veces al día, al ver estas grandes pinturas se sentirían parte, humilde si se quiere, de ese gran árbol en cuyas ramas habitaban otros tantos hermanos de religión que les habían antecedido en el tiempo, y que habían llevado vidas ejemplares y dignas de emulación ${ }^{4}$. La colocación en la caja de escalera, además, permitía al monje quiteño ir descubriendo los diferentes niveles de la pintura, no observando únicamente la parte inferior, sino pudiendo reconocer en las distintas ramas a los personajes más destacados, quienes a su vez solían estar identificados por cartelas o filacterias con su nombre.

Precisamente al hilo de esta idea, Sebastián señalaba cómo este tema encontraría los lugares adecuados para su exposición y lectura histórica, retórica y mística en iglesias, claustros, refectorios, bibliotecas y salas capitulares ${ }^{5}$. En el caso quiteño, fueron las cajas de escalera los espacios idóneos para tal fin. Así sucede en el convento de San Francisco, y también en San Agustín y la Recoleta de la Peña de Francia originalmente. En relación a los monasterios femeninos, el de Santa Clara conserva una versión escultórica del árbol dominico en la caja de escalera. Pero en América no siempre estuvieron pensadas estas pinturas para los claustros, sino que a veces fueron ideadas directamente para la iglesia ${ }^{6}$. Esta última ubicación, que hoy sí tiene La Regla de San Agustín, no fue la original ni nunca se pensó para las iglesias quiteñas.

${ }^{4}$ Donahue-Wallace apunta, en relación a las pinturas murales del convento agustino de Actopan, que estas servirían de inspiración a los frailes que estudiaban en el cenobio. De esta manera, cuando pasaban por las escaleras recordaban sus enseñanzas y entendían su llamada a la acción. Véase DONAHUE-WALLACE, Kelly: Art and Architecture of Viceregal Latin America, 1521-1821. University of New Mexico Press, Albuquerque, 2008, p. 50.

5 SEBASTIÁN, Santiago: El barroco iberoamericano. Mensaje iconográfico. Ediciones Encuentro, S.A., Madrid, 1990, pp. 289-290.

Stratton-Pruitt mantenía que los enormes cuadros sobre las genealogías de las órdenes religiosas son exclusivos de la Sudamérica virreinal, aunque también hay ejemplos novohispanos y peninsulares. Véase STRATTON-PRUITT, Suzanne L: “Árbol genealógico de la Orden Franciscana", en The Art of Painting in Colonial Quito. Saint Joseph's University Press, Philadelphia, 2012, p. 45. Así, en Montilla (Córdoba) hay un cuadro de grandes dimensiones de la Genealogía agustiniana, conservado en la antigua iglesia de los agustinos de la localidad, basado en el mismo grabado que el de Quito (de Oliviero Gatti), y en Granada se conservan dos pinturas de Risueño sobre la genealogía mercedaria, en sus ramas masculina y femenina.

${ }^{6}$ Los casos novohispanos que proporciona Melvin son significativos en este sentido. Véase MELVIN, Karen: Building Colonial Cities of God..., op. cit., p. 79. De esta manera, no sólo los frailes, sino también los fieles que entrasen a las iglesias, serían testigos de la importancia de la Orden a la que pertenecía el templo. 
En cuanto al momento de su realización, tres de las órdenes masculinas establecidas en la capital de la Real Audiencia -dominicos, franciscanos y agustinosencargaron estas pinturas en el siglo XVII. Por su parte, mercedarios y jesuitas constituyen casos diferentes. Para los primeros, hubo que esperar hasta mediados del siglo XVIII, cuando encontramos en Quito una pintura de esta iconografía que exhibía en un árbol los frutos principales de la orden. En cuanto a los jesuitas, no se conserva en la actualidad ninguna pintura que siga este esquema -ni aparece mencionada en el inventario de los bienes de los jesuitas de Quito, elaborado en 1784 tras su expulsión de los territorios de la monarquía hispánica ${ }^{7}$-.

A pesar de la indudable importancia que tiene el tema, este no ha suscitado el interés de muchos investigadores. Cabe destacar el estudio que en 1996 dedicó Pérez Morera a los árboles genealógicos franciscanos y dominicos en el arte virreinal, dejando de lado en cambio a las demás órdenes ${ }^{8}$. De una forma resumida, aportaba conocimiento sobre las fuentes grabadas y algunos ejemplos en América y Canarias. Pero en relación a Quito, sólo traía a colación una pintura y una escultura del árbol dominico, obviando otras versiones de esta iconografía y, de manera incomprensible, la gran pintura de la genealogía franciscana. Hubo investigadores que se referían de manera aún más parcial a esta iconografía, tratando algún que otro ejemplo suelto ${ }^{9}$. Ya en relación directa con el arte quiteño, hubo algunas aportaciones en la obra colectiva The Art of Painting in Colonial Quito ${ }^{10}$, en la que tuvimos ocasión de colaborar. En esta obra, concebida como un catálogo de pintura quiteña virreinal, figuraban algunos lienzos de los aquí tratados, aunque en esa ocasión analizados individualmente por otras colegas, sin ofrecer una visión de conjunto que se interesase por la trascendencia de esta iconografía.

Las pinturas y grupos escultóricos cuyo estudio abordamos en este trabajo tenían un claro precedente en relación tanto a la estructura como a la propia iconografía: el Árbol de Jessé, que representaba la genealogía de Cristo. Según Kroger y Granziera, las órdenes religiosas utilizaron precisamente esta imagen, aunque transformada en árbol genealógico de la orden, para su propia promoción y

${ }^{7}$ El inventario, transcrito por la historiadora ecuatoriana María Antonieta Vásquez Hahn, está reproducido en MORENO EGAS, Jorge y otros: Radiografía de la piedra: los jesuitas y su templo en Quito. FONSAL, Quito, 2008, pp. 387-429.

8 PÉREZ MORERA, Jesús: “El árbol genealógico...”, op. cit., pp. 119-126.

${ }_{9}$ Por ejemplo, MELVIN, Karen: Building Colonial Cities of God..., op. cit., pp. 7780, quien estudiaba dos pinturas, una del árbol franciscano y otro dominico, en conventos de Puebla y Oaxaca. O Santiago Sebastián, que dedicaba unas líneas al árbol genealógico franciscano en América, sin referirse en ningún momento a la gran pintura quiteña. Véase SEBASTIÁN, Santiago: El barroco iberoamericano. Mensaje iconográfico. Ediciones Encuentro, Madrid, 1990, p. 316. En cambio, no hacía mención a este asunto en su reconocida obra Iconografía e iconología del arte novohispano. Grupo Azabache, México, 1992.

10 The Art of Painting in Colonial Quito. Saint Joseph's University Press, Philadelphia, 2012. 
autoglorificación ${ }^{11}$. De esta iconografía primigenia, que tuvo una amplia difusión en la Edad Media, se conservan incluso algunos lienzos en América, que demuestran cómo en plena época barroca tenía vigencia el tema, aunque a veces añadiendo advocaciones locales al mismo ${ }^{12}$. La iconografía del Árbol de Jessé tuvo gran difusión merced a la estampa de Johannes Wierix (1573). Utilizando la estructura arbórea, resultaba sencillo sustituir a los miembros de la genealogía de Cristo por los individuos más destacados de cada orden. Pero es que los artistas americanos contaban además, en muchos de los casos, con estampas europeas realizadas por autores que, bajo supervisión de algún religioso de cada orden, darían con el modelo concreto a seguir en otros conventos. Respecto a los referentes gráficos, obviamente existen modificaciones que se aprecian en el estilo local, pero también existe una decisión de simplificar, siquiera someramente, el denso contenido de la estampa. Y ello sucede no en relación al número de figuras incluidas, sino a las numerosas cartelas que solían colocarse en los márgenes de los grabados. En la parte superior del árbol genealógico de cada familia religiosa, como remate del árbol suele aparecer la Virgen, siendo las advocaciones elegidas las más cercanas a la orden ${ }^{13}$.

\section{EL ÁRBOL DOMINICO: LA VIRGEN DE LA ESCALERA}

La primera representación del árbol genealógico de una orden religiosa en el arte de la Real Audiencia de Quito, que presenta características que luego se repetirán en las demás pinturas objeto de este estudio, pertenece a la Orden de Predicadores, y data de comienzos del siglo XVII. Según Gómez-Chacón, la representación del árbol genealógico de los dominicos, a modo de variante iconográfica del Árbol de Jessé, se difundió por los conventos observantes dominicanos europeos entre fines del siglo XV y comienzos del siguiente ${ }^{14}$. En esta ocasión, sería el pecho del santo español el núcleo del que saldrían las ramas cuyos frutos

${ }^{11}$ KROGER, Joseph y GRANZIERA, Patrizia: Aztec Goddesses and Christian Madonnas: Images of the Divine Feminine in Mexico. Ashgate Publishing, Ltd., Surrey, 2012, p. 107. Los autores yerran al afirmar tajantemente que las representaciones de este tipo desaparecen en Europa después del siglo XVI, pues a continuación mencionaremos algunos ejemplos que datan al menos de un siglo después.

12 Así sucede con el lienzo que representa el Árbol de Jessé con la Virgen de Guadalupe, pintura anónima custodiada en el santuario guadalupano de Acámbaro, Guanajuato, que reproducía Sebastián en un estudio publicado en 1992. Véase SEBASTIÁN, Santiago: Iconografía e iconología..., op. cit., p. 44.

13 Según Pérez Morera, la Virgen del Rosario para los dominicos, y la Inmaculada para los franciscanos. Véase PÉREZ MORERA, Jesús: "El árbol genealógico...”, op. cit., p. 120.

${ }^{14}$ GÓMEZ-CHACÓN, Diana Lucía: "Santo Domingo de Guzmán”, Revista Digital de Iconografía Medieval, vol. V, n 10, 2013, p. 97. https://www.ucm.es/data/cont/ 
son los más destacados hijos de Santo Domingo. Esta iconografía tenía como misión "potenciar el recuerdo de los años dorados de la orden y del carisma espiritual de su fundador, así como el de sus más destacados vástagos"15. El modelo grabado que en ciertas ocasiones se usó en América fue el de Adrian Collaert (Triumphus Martyrum Ordinis Praedicatorum) ${ }^{16}$. Pero en Quito no se sintió la necesidad de mostrar de esta forma a los dominicos más renombrados, quizás por contar desde temprano en la capital con la imagen de la Virgen de la Escalera como modelo válido para este propósito. Esta pintura presenta a Santo Domingo recostado, creciendo de él una vid en cuyo tronco aparece la Virgen del Rosario, y de cuyas ramas salen seis santos dominicos - Jacinto de Polonia ${ }^{17}$, Pedro Mártir, el beato Santiago de Bevagna, Vicente Ferrer y Antonino de Florencia-. El santo fundador sostiene una vara de lirios -símbolo de castidad y pureza-, junto a él un libro abierto - atributo intelectual o representación de las Sagradas Escrituras ${ }^{18}$ - y también un cachorro de can con una tea prendida entre las fauces ${ }^{19}$.

Esta imagen de La Virgen de la Escalera -llamada así por su emplazamiento originario en la caja de escalera de la recoleta dominica, hoy en el convento de Santo Domingo- tuvo cierta difusión en Quito, como demuestran algunas versiones pictóricas y escultóricas de los siglos XVIII y XIX. Según Lepage, la pintura está basada en un grabado de Franco Giacomo, y la fuente de inspiración es el Árbol de Jessé. La que hoy se custodia en la capilla de la Escalera de la iglesia del convento de Santo Domingo procede de la Recoleta de la Peña de Francia,

docs/621-2013-12-14-09.\%20Santo\%20Domingo\%20de\%20Guzm\%C3\%A1n.pdf (Consultado el 15/08/2015).

15 Idem.

16 Véase la pintura mural conservada en el ex-convento Dominicano de Santiago Apóstol, Culiapán, Oaxaca, México, reproducida en la web del Project on the Engraved Sources of Spanish Colonial Art (PESSCA). http://colonialart.org/archives/subjects/ pious-allegories/congregational\#c2238a-2238b (Consultado el 15/09/2015).

${ }^{17}$ Este, por cierto, actualmente con unos rasgos indígenas que no corresponden ni con su iconografía original, ni con la que había ideado fray Pedro Bedón, tal y como se puede constatar en la copia de Albuja.

18 GÓMEZ-CHACÓN, Diana Lucía: "Santo Domingo de Guzmán...”, op. cit., pp. 91-92.

${ }^{19}$ Este detalle iconográfico procede de las visiones de Juana de Aza, madre de Santo Domingo, a quien se reveló que lo que llevaba en el vientre no era un niño sino un cachorro con la mencionada tea, lo que simbolizaba que su vástago sería un predicador insigne, que con el ladrido de su santa palabra, excitaría a la vigilancia de las almas dormidas en el pecado y llevaría por todo el mundo el fuego que Jesucristo vino a traer a la tierra. Véase GELABERT, Miguel y MILAGRO, José María: Santo Domingo de Guzmán visto por sus contemporáneos. Biblioteca de Autores Cristianos, Madrid, 1966, pp. 148-149. En las representaciones quiteñas, tanto más apropiado el detalle de la tea, y más aún el de situar al perro sobre el orbe, alusión a la presencia de la orden dominica en todo el mundo. 
fundada en 1600, y fue realizada por fray Pedro Bedón poco después (Figura 1). La pintura trabajada por uno de los principales artistas del primer tercio del siglo XVII en Quito fue trasladada desde su primer emplazamiento y pasada de su original sobre muro al lienzo en 1909. Los retoques resultan apreciables en grado sumo, pues incluso partes tan significativas como las caras de la Virgen y Santo Domingo parecen haber sido retocadas, así como las manos de María. Un detalle iconográfico de importancia que se observa en esta obra, pero en ninguna de sus versiones posteriores -ni pictóricas ni escultóricas-, es la pequeña figura del Niño surgiendo de una flor nacida del corazón sobre el pecho de la Virgen. Debe de ser un añadido que date de la época de su traslado, ya que no aparece en ninguna de las otras piezas, las más tardías de ellas realizadas en el siglo XIX. Es más, en una copia realizada por Joaquín Albuja -responsable de trasladar al lienzo la obra original para salvarla de su desaparición-, y con destino a la Recoleta convertida ya en cenobio de religiosas del Buen Pastor, tampoco aparecen ni el Niño ni el corazón ${ }^{20}$. Un detalle menor que también se modificó es la corona, pues en todas las versiones posteriores tiene unos imperiales que no figuran en la original, no sabemos si por haberse alterado en la época de su traslado o en una restauración posterior -que parece lo más lógico-, o bien por deberse a una variación del siglo XVIII que tuviera éxito.

Como indicamos antes, la iconografía originalmente plasmada por fray Pedro Bedón en la Recoleta debió causar cierto interés entre los fieles quiteños. La idea de destacar la relación entre la Virgen del Rosario y Santo Domingo mediante la vid de la que surgen los santos dominicos tuvo éxito en los siglos venideros, y así se encuentran muestras en pintura y escultura. La clave de la gran aceptación de esta iconografía nos la puede dar el religioso sevillano Francisco Antonio de Montalvo, quien en 1687 señalaba que los prodigios de la imagen presentaban "continuamente la devoción de los fieles con sus plegarias y votos" ${ }^{\text {"21 }}$. Lo

${ }^{20}$ La pintura de Albuja tiene una inscripción en la parte inferior en la que señala que es copia fiel del original, colocada en el lugar que aquella había ocupado hasta 1871. El lienzo está reproducido en VARGAS, José María: Patrimonio Artístico Ecuatoriano. Fundación Fr. José María Vargas y TRAMA Ediciones, Quito, 2005 ( $3^{\mathrm{a}}$ edición, corregida y aumentada), p. 280.

En cuanto al formato de la pintura, el traslado a lienzo efectuado por Albuja no fue la solución definitiva para su conservación. El estado de deterioro que presentaba a comienzos del siglo XXI obligó al FONSAL a intervenir, restaurando la obra y transfiriéndola a un soporte sólido - un bastidor de aluminio en esta ocasión-. Véase LEPAGE, Andrea C: "Virgen de la Escalera", en The Art of Painting in Colonial Quito. Saint Joseph's University Press, Philadelphia, 2012, p. 22.

${ }^{21}$ MONTALVO, Francisco Antonio de: Milicia angelica del cingvlo de S. Thomas de Aqvino, quinto doctor de la Yglesia. Iuan Iago Komarek, Roma, 1687. El fragmento del texto fue reproducido por VARGAS, José María: Patrimonio Artístico Ecuatoriano..., op. cit., p. 277. 
cierto es que, a diferencia de las otras pinturas de genealogías de la orden -que no tuvieron versiones posteriores destinadas al ámbito conventual ni al doméstico-, la Virgen de la Escalera dio el salto al medio y pequeño formato, desde el lienzo a la madera. De entre las varias pinturas de este asunto, que presentan las mismas características compositivas con pequeñas variantes, la de mayor calidad es la que con el número de inventario AC.1351 conserva la Casa de la Cultura Ecuatoriana en su Museo de Arte Colonial (Figura 2). Quizás, las mayores diferencias se encuentran en los gestos de los santos surgidos de las ramas del árbol y en la paleta elegida, más propia del gusto quiteño de fines del siglo XVIII y comienzos del XIX. Respecto a la original también destaca un cambio en los racimos de uva, pues si los primeros eran de uva tinta, los segundos lo son de uva blanca, más acorde con la entonación general de la pintura. Por otra parte, los santos que aparecían identificados con sus nombres sobre las flores ${ }^{22}$, no tienen identificación en este cuadro, más allá de sus símbolos parlantes. Otras dos versiones pictóricas de este asunto conserva también la Casa de la Cultura Ecuatoriana en los fondos de su Museo de Arte Colonial. La que tiene el número de inventario AC.1342 es más cercana a la pintura de la Recoleta de la Peña de Francia, con el perro y los santos dispuestos en la misma posición y lugar ${ }^{23}$. Ni estas dos ni la número AC.0751, antes mencionada, tienen tampoco el Niño ni el corazón en el pecho.

Junto a las pinturas citadas cabe destacar algunas tallas en madera policromada de fines del siglo XVIII, de medio formato, y conservadas en monasterios de clausura. Así, la del Museo del Monasterio de Santa Catalina de monjas dominicas (1,25 x 0,95 x 0,41 m.), que sigue de cerca el mismo modelo (Figura 3). El grupo hace gala de un trabajo exquisito de la madera. Como en su referente pictórico, Santo Domingo reposa tumbado en la parte inferior, junto a un libro y un perro. Tras él se levanta un árbol, cuyo tronco ocupa la Virgen, coronada y con cetro ${ }^{24}$, pero sin el Niño ni el corazón que aparecían en la pintura mural de la Recoleta de la Peña de Francia. Seis santos dominicos surgen de las ramas del árbol, cuajado de racimos de uvas, como en la pintura. Los dominicos aparecen de medio cuerpo, vistiendo el hábito de la orden. La novedad radica en que el árbol está rematado por el grupo de la Trinidad en su forma ortodoxa de representación. De esta manera, se establece un vínculo directo entre el fundador de la orden de Predicadores, la Madre de Dios y la Trinidad. El grupo escultórico en madera que Pérez Morera sitúa en la escalera principal del Monasterio de Santa Clara $^{25}$, muy similar, es prueba de la extensión de esta iconografía.

${ }^{22} \mathrm{~A} 1$ menos, algunos de ellos, no sabemos si añadidos en época posterior.

${ }^{23}$ En esta pintura, el santo no lleva la vara de lirios, y no se aprecia si hay orbe bajo el perro. Por otra parte, no aparece el libro abierto, como en otras imágenes quiteñas.

${ }^{24} \mathrm{Y}$ suponemos que originalmente también con rosario, aunque hoy falta este detalle.

${ }^{25}$ PÉREZ MORERA, Jesús: "El árbol genealógico...”, op. cit., p. 121. 
A diferencia del caso de los dominicos de Quito, del resto de órdenes establecidas en la ciudad sólo se conserva una pintura de su árbol genealógico. De agustinos y franciscanos se realizaron dos lienzos de grandes dimensiones concebidos para las cajas de escalera de estos cenobios, mientras que los mercedarios nos han legado un pequeño cuadro de similar tema ${ }^{26}$.

\section{LA REGLA DE SAN AGUSTÍN}

La pintura que conservan los agustinos quiteños es, por su calidad artística, la más sobresaliente de las relacionadas con el árbol genealógico de una orden religiosa en Quito (Figura 4). Fue realizada por Miguel de Santiago y sus colaboradores entre 1656 y 1658, suponiendo el broche de oro a la serie sobre la vida del santo terminada en 1656 y destinada a ornar el claustro del convento. En relación a La Regla, su ubicación original fue la caja de escalera del convento - de hecho, se la conocía como "el cuadro de la Grada", según se recoge en inventario realizado de los bienes del convento ${ }^{27}$. Actualmente se exhibe en el presbiterio de la iglesia, perdiendo parte de su sentido original. De esta enorme pintura ya escribimos un artículo hace unos años. En él analizamos la iconografía, el estilo, dimos a conocer la fuente grabada utilizada por Miguel de Santiago, y también el periplo de la pintura por las diferentes dependencias del convento ${ }^{28}$. Gisbert indicaba, en relación al arte de los Andes, que junto al cuadro quiteño había algunos lienzos de grandes dimensiones que mostraban a San Agustín con todos los santos de la orden, aunque no indicaba más ejemplos ni especificaba si estos también utilizaban el árbol como estructura ${ }^{29}$. En la iglesia de los agustinos de Montilla (Córdoba) se conserva otra gran pintura que se basa en las estampas de Oliviero

${ }^{26}$ Debido a las dimensiones de esta pintura, que no son comparables a las inmensas telas de agustinos y franciscanos, probablemente la ubicación original fuera distinta de las cajas de escalera.

${ }^{27}$ Archivo Histórico del Convento de San Agustín de Quito (A.H.S.A.), Tomo 94: Libro de Fábrica 1871-1920, fol. 79 v. En este inventario se indica que, al momento de realizarlo, el cuadro presidía el presbiterio de la iglesia. Sería después cuando se colocase en el lado derecho del presbiterio, enfrentado al gran cuadro de Luis Cadena La conversión de San Agustín. Por otra parte, en nota firmada el 29 de mayo de 1881 por el padre Ángel Fatteschi, se indica que se colocó el "Cuadro de la grada", aunque no se hace mención más precisa de dónde ni si se refiere a La Regla. Véase A.H.S.A., Vol. 84. "Libro n 218, Inventario del Convento e Iglesia de San Agustín, 1880", fol. 67 r.

${ }_{28}$ JUSTO ESTEBARANZ, Ángel: "El cuadro grande que llaman de la gerarquía: la Regla de San Agustín de Miguel de Santiago", Quitumbe, 16, 2011, pp. 159-178.

${ }^{29}$ GISBERT, Teresa: "El arte agustiniano en los Andes", en Iconografía agustiniana. Institutum Historicum Augustinianum, Roma, 2001, p. 299. Uno de ellos es el que se conserva en la Iglesia de San Agustín de Lima, atribuido a Basilio Pacheco y realizado en el siglo XVIII. Véase http://colonialart.org/artworks/1947B (Consultado el 27/09/2015). 
Gatti, y que también debió de ser pintada en el siglo XVII ${ }^{30}$. Junto con el cuadro conservado en el convento quiteño y el de Montilla, existen otras muestras que derivan del mismo grabado. Entre ellas, la de Basilio Pacheco en la Iglesia de San Agustín de Lima, que corresponde a una simplificación muy acusada del original italiano ${ }^{31}$.

Como la pintura del convento quiteño ya la analizamos por extenso en otra publicación, queremos resaltar aquí algunos aspectos relacionados con la iconografía del árbol. Si en los lienzos franciscano, dominico y mercedario quiteños el fundador es la base del árbol -o quien sujeta el tronco, en la zona inferior de la pintura-, aquí nos encontramos con una distribución distinta. San Agustín no sirve de raíz o soporte del árbol, sino que se sitúa en el centro mismo, concretamente en un tronco que queda casi completamente cubierto. Y ello se debe a que el obispo de Hipona es el centro real y figurado de la composición. De él emana la regla asumida por una cantidad ingente de corporaciones religiosas, agustinas o no. Ello tiene una importancia capital, pues en la zona inferior encontramos a representantes de las religiones mercedaria, dominica y franciscana, entre otras, que reconocen el magisterio del santo africano. Las ramas del árbol están ocupadas por santos de la orden agustina. En este punto se respeta la tónica general de la iconografía estudiada en este artículo. Eso sí, ya no es únicamente la Virgen quien remata la composición, sino la Trinidad, a quien acompañan la propia Virgen y San Juan Bautista. Es decir, en esta imagen nos encontramos el rompimiento de gloria más poblado de todas las pinturas quiteñas del tema realizadas en el siglo XVII. Habrá que esperar a la siguiente centuria para ver cómo, en dos ejemplos escultóricos dominicos, aparece la Trinidad sobre la Virgen, y en el lienzo de El Tejar, una nutrida representación de ángeles rodeando a la Virgen de la Merced con el Niño. Aunque en la pintura mercedaria el rompimiento de gloria merezca proporcionalmente un espacio mayor, el hecho de que los agustinos quisieran situar a la Trinidad en la pintura incide en la trascendencia del mensaje de Agustín, el Águila de Hipona, quien mejor se adentró en los misterios de la Trinidad.

\section{EL ÁRBOL GENEALÓGICO FRANCISCANO}

Según Stastny, es sobre todo en los conventos franciscanos donde se encuentran lienzos de dimensión mural representando el árbol como esquema sinóptico

${ }^{30} \mathrm{El}$ conjunto, que constaba de doce estampas y tenía formato apaisado, lleva por título MYSTICAE AUGUSTINENSIS. EREMI. SACRUM. GLORIAE. DECORISQ. THEATRUM.

${ }^{31} \mathrm{Y}$ de un inferior nivel técnico a la pintura quiteña, pudiendo observarse aquí la mano de colaboradores de Pacheco. 
de la genealogía de las órdenes religiosas" ${ }^{32}$ En ellos figura "la sucesión cronológica de los fundadores, santos e individuos destacados que integraron la congregación". Pero el investigador peruano dejaba de lado el inmenso cuadro de los franciscanos de Quito (Figura 5), refiriéndose solo a los ejemplos peruanos y mexicanos, como hizo Pérez Morera.

La fuente grabada del complejo cuadro quiteño es una estampa de Peeter de Jode I, que reproducía el árbol cuajado de miembros de la orden seráfica (Figura $6)^{33}$. La imagen mostraba en la parte inferior a San Francisco sujetando el enorme árbol cuyo tronco se coronaba con la Virgen, y de cuyas ramas florecían a modo de frutos los santos de la orden. El fundador viste el hábito franciscano, lleva puesta la capucha y el rosario colgando del cordón franciscano. Junto a él, y arrodillados seis a cada lado, oran los doce primeros frailes de la orden. En la estampa, San Francisco mostraba tres libros abiertos, con las tres reglas de la orden, más la de Santa Clara y la de la orden Tercera. Al fondo, tras los religiosos, aparecía un paisaje con una iglesia y un crucero de piedra sobre un montículo ${ }^{34}$. El árbol franciscano consta de un robusto tronco del que parten trece ramas a cada $1 \mathrm{ado}^{35}$, en las que de modo jerárquico y cronológico se han colocado más de 800 personajes. Las dos primeras ramas están reservadas a santos y mártires de la primera orden. Por su parte, la tercera y cuarta ramas están ocupadas por la jerarquía eclesiástica de progenie franciscana - papas, cardenales, patriarcas, arzobispos y obispos, cada uno de los cuales presenta su blasón familiar-. La quinta y sexta ramas están dedicadas a albergar a emperadores, reyes, príncipes y reinas, también acompañados por su

${ }^{32}$ STASTNY, Francisco: Síntomas medievales en el "barroco americano". Instituto de Estudios Peruanos, Lima, 1993, p. 19. file://C:/Documents\%20and\%20Settings/pdi/ Mis\%20documentos/Downloads/5945-8-1.pdf (Consultado el 15/08/2015). Para el autor, esta iconografía del árbol genealógico integraba el grupo de las que tenían un origen medieval y, salvo algunas excepciones europeas, fueron trabajadas mayoritariamente -"sistemáticamente" en palabras del propio Stastny-en América durante el siglo XVII.

${ }^{33}$ Véase http://colonialart.org/archives/locations/ecuador/provincia-de-pichincha/ ciudad-de-quito/museo-fray-pedro-gocial\#c1915a-1915b (Consultado el 27/09/2015). En realidad, y como sucedía con el modelo grabado de la Genealogía agustina, son 12 estampas las que componen la imagen, con un tamaño total de 1,96 x 1,28 m. Véase PÉREZ MORERA, Jesús: "El árbol genealógico...”, op. cit., p. 123. La fecha de realización es 1626, siendo aprobada por el arzobispo de Amberes, Joannes Malderus, el 15 de abril de ese año.

${ }^{34}$ Rodríguez Escudero destacaba el sabor flamenco del paisaje de fondo. Véase RODRÍGUEZ ESCUDERO, José Guillermo: "El Grabado de la Familia Franciscana. Venerable Orden Tercera. Santa Cruz de La Palma". En http://www.liceus.com/cgi-bin/ac/pu/ escudero/Grabado_familia_franciscana.asp (Consultado el 24/08/2015).

${ }^{35}$ En el cuadro de Quito son también 13 ramas, y no 12, como apuntaba StrattonPruitt. Véase STRATTON-PRUITT, Suzanne L: “Árbol genealógico de la Orden Franciscana...", op. cit., p. 45. 
blasón correspondiente. Sobre ellos, y en cuatro ramas, aparecen duques, marqueses y condes, frailes y sores, y hermanos terciarios de los dos sexos, integrantes de la nobleza española y europea, también con escudos ${ }^{36}$. En la undécima rama descansan las ramas femeninas y de clausura de la orden seráfica -clarisas, concepcionistas, monjas de la orden de la Anunciación, capuchinas y hermanas terciarias de clausura-, y en el extremo derecho de esta rama, hermanos de la orden Tercera de Penitencia de vida comunitaria. En la duodécima rama figuran frailes, beatos, santos mártires y varones preclaros de las ramas de franciscanos reformados -observantes, recoletos y descalzos-. La decimotercera rama está destinada a los capuchinos. La Inmaculada corona el árbol, simbolizando el apoyo y defensa de este dogma por parte de los franciscanos.

En la misma estampa se basó el anónimo pintor de la menos hábil muestra conservada en la Iglesia de San Francisco de Arequipa (Perú), realizada también en el siglo XVII e identificada por Ojeda y Pérez Morera, o en la más sólida de Juan Espinoza de los Monteros en el cenobio franciscano de Cuzco (Perú), fechada en 1655, y que mantiene las cartelas. Incluso la versión más libre de Cristóbal de Talavera (1731, Puebla) obedece a la misma fuente. A estas podríamos unir también la que conserva el Museo de Arte Colonial de San Francisco (Santiago de Chile), de formato más cuadrado y con variantes iconográficas de interés. Otra interpretación más libre del modelo, la de la iglesia de los franciscanos en Puebla, presenta conexiones con las anteriores, como la disposición de la Inmaculada, aunque en este caso con el Crucificado coronando la composición ${ }^{37}$.

La fecha de realización del gran cuadro de los franciscanos de Quito debe estar en torno a los años centrales del siglo XVII. Según Stratton-Pruitt, la pintura de Cuzco, datada en 1655, podría ser orientativa del momento en que se encargó la obra quiteña ${ }^{38}$. Precisamente, en fechas cercanas encomendaron los agustinos de la ciudad a Miguel de Santiago la gran pintura de su orden. No es de extrañar que ello animase a los franciscanos a querer exhibir su genealogía tal como lo habían hecho los hijos de San Agustín, aunque al no estar fechada esta pintura, no sabemos cuál de las dos fue la primera. El autor del cuadro de los franciscanos quiteños, a fin de facilitar la identificación de los numerosos personajes, tradujo las cartelas que figuran bajo el busto de cada uno de ellos, adheridas a las ramas o al tronco del árbol. Lo que sí mantuvo en el original latín fueron la filacteria superior ${ }^{39}$, y las que contenía el libro que sostiene el santo de Asís. En el lienzo quiteño, se han eliminado los libros con las reglas de Santa Clara y de la Tercera Orden, dejando solo la de los Hermanos Menores. Además de esto, los

${ }^{36}$ PÉREZ MORERA, Jesús: “El árbol genealógico...”, op. cit., p. 124.

${ }^{37}$ La pintura poblana, de peor factura técnica que la quiteña, data de 1731 . Véase MELVIN, Karen: Building Colonial Cities of God..., op. cit., pp. 77-78.

${ }^{38}$ STRATTON-PRUITT, Suzanne L: “Árbol genealógico...", op. cit., p. 45.

39 EPILOGUS TOTIUS ORDINIS SERAPHICI P. S. FRANCISCI. 
dos escudos que en la estampa se habían colocado en la parte superior -ambos de la orden franciscana: el de los brazos de San Francisco y Cristo ante la cruz, y el de las llagas-, aquí se han situado en las esquinas inferiores. Así, los religiosos tendrían un acceso mucho más directo a su contemplación. Al subir por las escaleras del convento, los frailes quiteños verían los escudos de la orden seráfica, a su fundador y a los doce primeros hermanos franciscanos, que serían ejemplo de vida para todos ellos.

Un hecho que merece la pena destacar, a pesar de las diferencias apreciables entre las pinturas quiteñas de San Francisco y de San Agustín, es que los artífices locales han tomado algunas decisiones similares. Por ejemplo, Miguel de Santiago y el autor de la pintura de San Francisco han prescindido de los escudos de las esquinas superiores de la composición -aunque en la pintura de los franciscanos sí aparecen dos en las esquinas inferiores, como en la estampa flamenca-. Por otra parte, ambos han optado por suprimir las cartelas dispuestas a los lados y en la zona inferior de los grabados. Ya de por sí las imágenes son complicadas y recargadas de figuras como para añadir más información con letra muy pequeña. Por ello se decidió eliminarlas.

Si franciscanos y dominicos tuvieron una larga tradición de árboles genealógicos de la orden, más excepcional fue el caso mercedario. No obstante, algunos ejemplos realizados en época barroca aún se exhiben en monasterios y colecciones $^{40}$. Se conserva una pintura en la Recoleta de El Tejar, de tamaño mucho menor a los otros cuadros $(151 \times 121 \mathrm{~cm})$, que Pacheco Bustillos fecha en la segunda mitad del siglo XVIII (Figura 7) ${ }^{41}$. San Pedro Nolasco, fundador de la orden redentora de cautivos, aparece de pie, en la mitad inferior central de la composición. El santo mira hacia abajo, dirigiendo la mirada del espectador hacia la cartela que lo identifica como fundador de la orden mercedaria ${ }^{42}$. El religioso oriundo de Barcelona sujeta el tronco con su mano izquierda, como lo hacía San Francisco en el cuadro de su convento quiteño. Y ello no es casualidad. Esta es la

${ }^{40}$ Alonso Aguado señala las dos pinturas de José Risueño en el Museo de Bellas Artes de Granada: Alegoría de la Fundación de la Orden Mercedaria y Santa María de Cervelló y la rama femenina de la Merced, más otras tres en América: dos en Toluca y Puebla, Árbol de la Merced, y la que representa el Árbol de los Mártires Mercedarios de Valdivia, Chile. Véase ALONSO AGUADO, Mario: "Árbol genealógico mercedario. Una llamativa iconografía de la época colonial”. En http://lapiedad1578.blogspot.com.es/2012/11/arbolgenealogico-mercedario-subasta.html (Consultado el 10/08/2015).

${ }^{41}$ PACHECO BUSTILLOS, Adriana: "Árbol genealógico de la orden mercedaria", en The Art of Painting in Colonial Quito. Saint Joseph's University Press, Philadelphia, 2012, p. 222. La misma pintura aparece reproducida y descrita someramente en VÁSQUEZ HAHN, María Antonieta y ORTIZ CRESPO, Alfonso: Historia y Arte en El Tejar de la Merced. FONSAL, Quito, 2010, p. 167.

${ }^{42}$ N.P. S. PEDRO NOLASCO FUNDADOR DEL SAGDOR Y MILITAR ORDEN DE NA S DE LA MERCED REDMCION DE CAUTIVOS. 
pintura que, aunque muy simplificada, sigue de una manera más evidente el modelo franciscano, con el fundador de pie en la parte inferior, los santos principales de la orden en el tronco, otros en las ramas, y todo ello rematado por la Virgen. Aunque existen precedentes iconográficos de esta pintura dentro de la orden mercedaria, es más común que San Pedro Nolasco aparezca tumbado bajo el tronco del árbol que sujeta con su brazo izquierdo -así lo hace en la pintura del granadino José Risueño conservada en el Museo de Bellas Artes de Granada, y en otras dos reproducidas por Alonso Aguado, además en las pinturas dominicas antes analizadas-. El precedente mercedario de esta disposición se encontraría en otro cuadro de Risueño en el propio museo granadino - Alegoría de la rama femenina de la orden mercedaria, realizado hacia 1693-1712-, donde la Virgen de la Merced y Santa María de Cervelló, de pie, sostienen el árbol. En la pintura de la Recoleta de El Tejar, es San Ramón Nonato quien, dotado de custodia y palma de martirio -siempre de medio cuerpo, como los demás santos- figura bajo el rompimiento de gloria en que aparece la Virgen de la Merced con el Niño, ambos con escapularios de la orden ${ }^{43}$. En la rama izquierda figuran, identificados por cartelas y por sus símbolos parlantes, San Pedro Pascual (o Pascacio), San Serapio y el Venerable Fray Juan Falconi de Bustamante (identificado por error por Pacheco Bustillos como Pedro Falcón). A la derecha, representados del mismo modo, San Pedro Armengol, Santa María del Socorro -es decir, Santa María de Cervelló- y el Venerable Fray Pedro Uraco. Pacheco Bustillos señala que todos estos personajes habían sido canonizados en el siglo XVII. Pero San Serapio, representado con hábito mercedario y gola - quizás para aludir a su anterior vida militar-, fue canonizado en 1743. Ello podría llevar la fecha de realización de la pintura hasta un momento posterior, probablemente en el tercer cuarto del siglo XVIII. Tras el fundador aparece un paisaje montañoso que Pacheco Bustillos relacionó con el medio ecuatoriano, y una iglesia que aludiría a la misión evangelizadora de los mercedarios. En cuanto al rompimiento de gloria, el grupo de la Virgen y el Niño está rodeado de numerosos querubines, así como de cuatro ángeles que visten atuendos de diferentes colores. Uno de ellos viste a modo de rey, otro de soldado (¿San Miguel?) y otro lleva un libro en sus manos.

Al hilo del análisis de esta pintura, una cuestión sobre la que merece la pena reflexionar es sobre qué especie de árbol se representa en cada caso. En todos, se tiende a una cierta indefinición, ya que no son fieles representaciones de cada especie. De ello dan muestra las pinturas de los franciscanos y sobre todo de los agustinos, donde apenas es apreciable el árbol, relegado a un discretísimo plano en relación a los personajes representados. La más reconocible de las especies

${ }^{43}$ Pacheco Bustillos sostiene que el santo que figura bajo la Virgen es San Raimundo de Peñafort, llamado San Ramón Nonato, pero este dato parece deberse a una confusión, pues el primero fue un religioso dominico, no mercedario. Véase PACHECO BUSTILLOS, Adriana: “Árbol genealógico de la orden mercedaria...”, op. cit., p. 222. 
vegetales es la que figura en las pinturas del árbol dominico: una viña. Para las pinturas dominicas está claro: los racimos de uvas identifican a la vida que, no obstante y a pesar de tener unos brazos de tallos ondulados, se dota de un fuerte tronco, simbolizando la firmeza de la orden en su cometido. Por su parte, para los mercedarios, el árbol seleccionado es un olivo, que se identifica con San Pedro Nolasco ${ }^{44}$.

\section{CONCLUSIÓN}

Como hemos podido ver en este trabajo, en el siglo XVII las órdenes religiosas establecidas en la capital de la Real Audiencia de Quito deciden encargar la realización de enormes pinturas sobre lienzo de carácter alegórico que mostrasen la genealogía de la orden. El modelo elegido, partiendo del esquema del Árbol de Jessé, ampliamente divulgado desde la Edad Media, presentaba un árbol cuyo tronco salía del fundador de la orden o era agarrado por este, y sobre cuyas ramas descansaban los miembros más destacados de la orden a modo de los frutos de ese árbol. La forma de representar a la familia en las ramas a modo de fruto varía entre unas pinturas y otras, pues si en el mural dominico y los lienzos de San Francisco y de la recoleta mercedaria los santos aparecen de busto, en la gran pintura de los agustinos figuran tanto bustos como santos de cuerpo entero, que además harán gala de un mayor naturalismo en su representación. La comisión de estos lienzos a artistas locales por parte de los religiosos no fue una decisión en absoluto gratuita. Sabemos que dos de ellos (Fray Pedro Bedón y Miguel de Santiago) eran los principales pintores quiteños de su tiempo. Los otros autores, aún no identificados, debieron de gozar también de una merecida fama entre el clero regular de la ciudad para que se decidiese a contratarlos para estas obras. Había toda una intencionalidad en ello. Que se encargasen estas pinturas a los artistas más valorados tiene un claro significado: se quería representar los frutos gloriosos de la orden con las mejores garantías posibles de que las pinturas pudieran plasmar la relevancia de cada orden a través de sus hijos más importantes. Si los dominicos fueron los primeros en plantear la iconografía -y no en su convento principal de la ciudad, sino en la Recoleta de la Peña de Francia-, sería a mediados del siglo XVII cuando agustinos y franciscanos abordasen, todavía a mayor

\footnotetext{
${ }^{44}$ En su hagiografía del fundador de la orden de la Merced, Colombo contaba cómo para la fundación del convento de Arguines se encontró un olivo con una imagen de la Virgen en su interior, e iluminado por unas luces sobre él. Véase COLOMBO, Felipe: Vida del glorioso patriarca San Pedro Nolasco, fundador del orden real y militar de Maria Santissima de La Merced o Misericordia, redempcion de cautivos. Antonio Marín, Madrid, 1769, pp. 299-300. Al santo, entre otros atributos, se lo representa con un ramo de olivo.
} 
tamaño, estas pinturas genealógicas ${ }^{45}$. Habría que esperar al XVIII para que los mercedarios afrontasen la iconografía, aunque a menor tamaño y en la Recoleta. La aparición de esta representación mediada la centuria ilustrada, unidad a las varias versiones del árbol dominico fechables incluso a comienzos del XIX, hablan de la pervivencia de esta iconografía en la ciudad andina.

Fecha de recepción: 15 de septiembre de 2015.

Fecha de aceptación: 20 de noviembre de 2015.

${ }^{45}$ La gran pintura dominica que mostraba al santo fundador con la Virgen y otros santos de la Orden, conservada en el convento de Santo Domingo, no tenía esta iconografía exactamente, sino que presentaba a la Virgen del Rosario con santos dominicos, y se hallaba colocada en el transepto de la iglesia. Era una pintura mural, cuya realización se puede fechar hacia 1620. En ella, junto a los santos dominicos figuraba Sebastián Dávila, maestro carpintero español que realizó las techumbres de madera de la iglesia dominica. Hacia 1730 se colocó sobre ella un lienzo que representa a la Virgen protectora de la orden dominica. Véase WEBSTER, Susan V: Quito, ciudad de maestros: arquitectos, edificios y urbanismo en el largo siglo XVII. Ediciones Abya-Yala, Quito, 2012, pp. 107-111. Por lo tanto, sería la Orden de Predicadores la primera que en Quito introdujo esas composiciones de la Virgen protegiendo a los santos de la orden, y también la que optó por trasladar el esquema del árbol de Jessé a esta idea, así como la que más ímpetu puso en la misma, ya que hemos contabilizado seis piezas de esta iconografía -cuatro pinturas y dos esculturas-. 


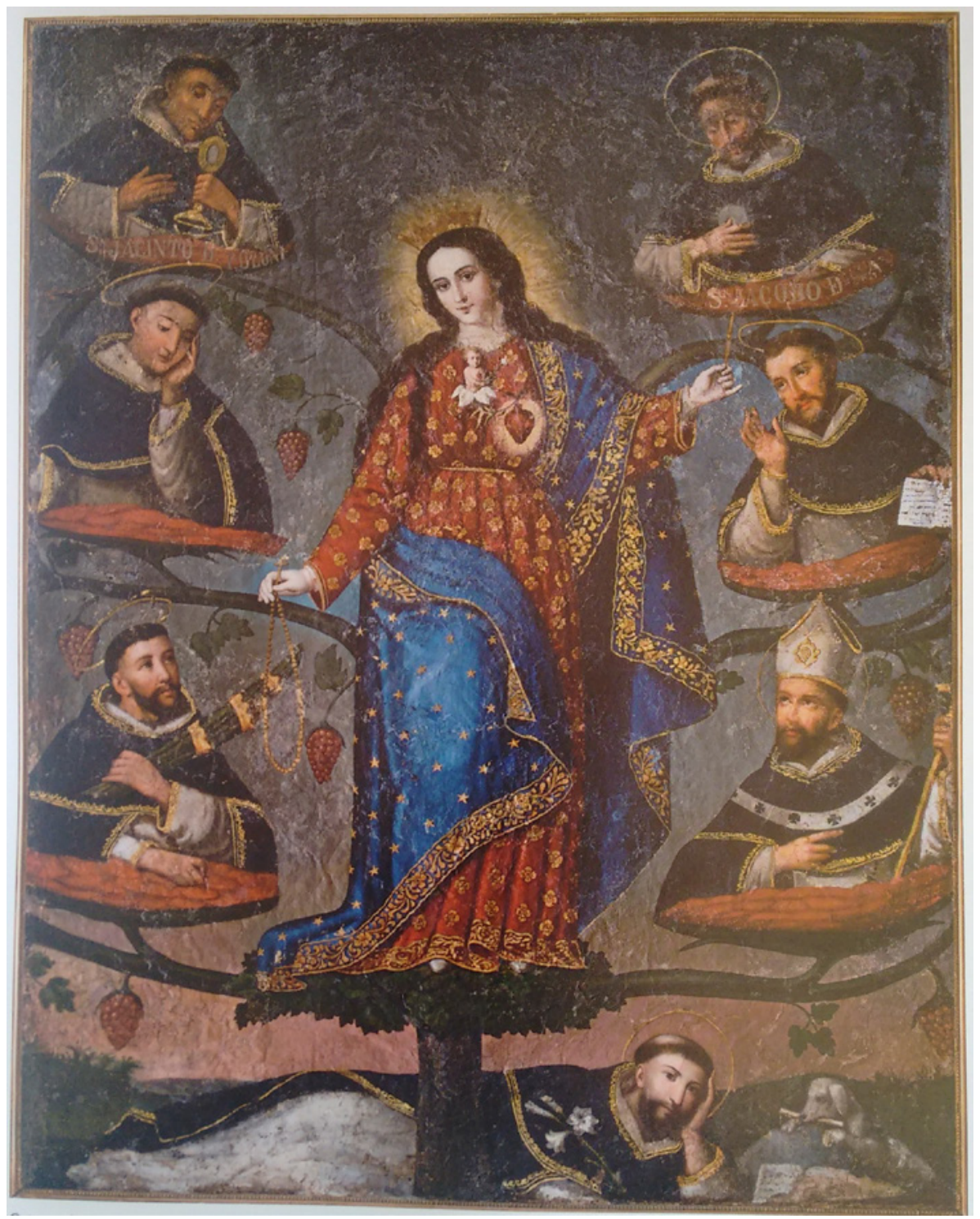

Figura 1. Fray Pedro Bedón. Virgen de la Escalera (Capilla de la Escalera, iglesia del convento de Santo Domingo, Quito, después de 1600). 


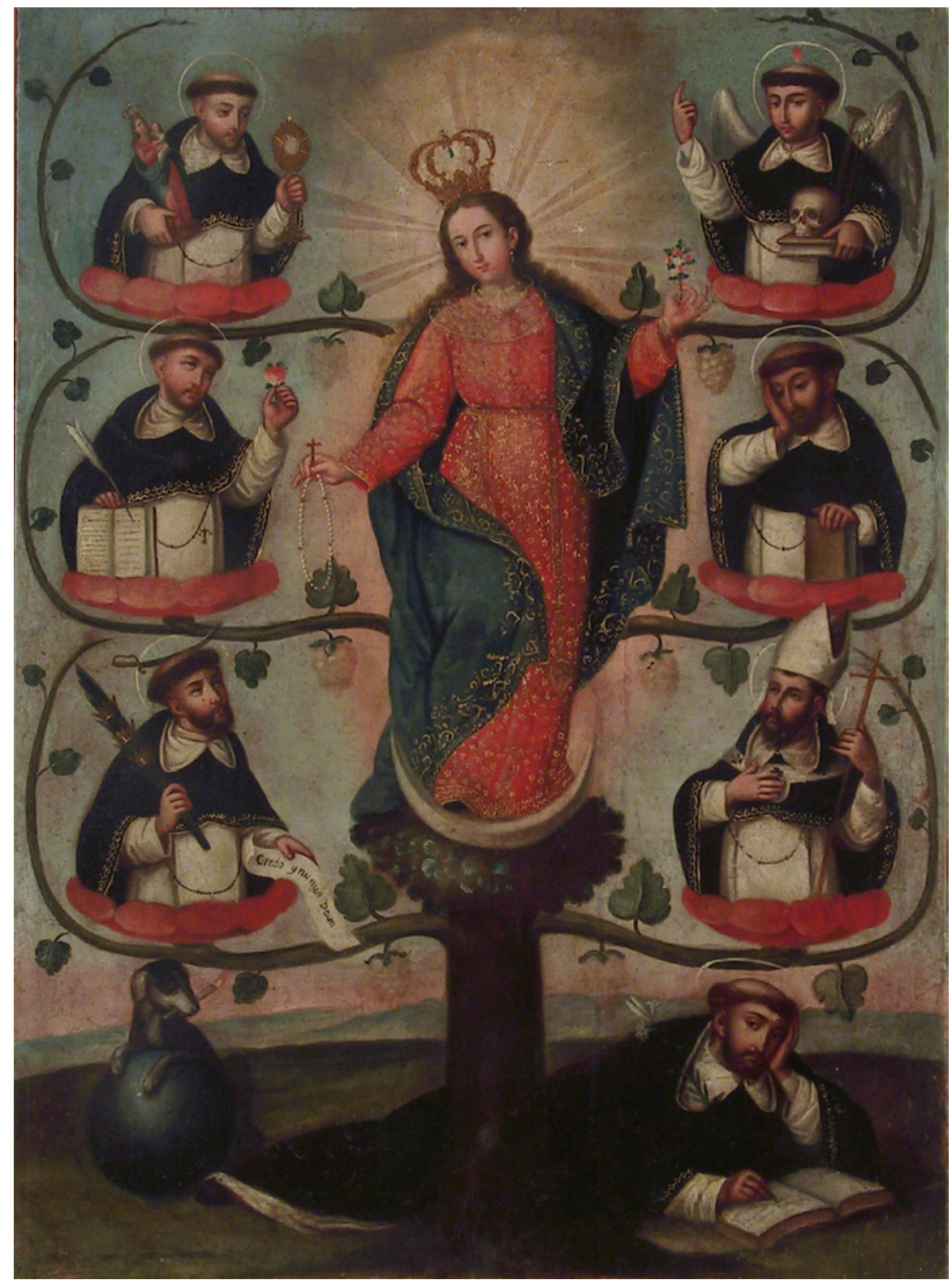

Figura 2. Anónimo. Virgen de la Escalera (Museo de Arte Colonial. AC.1351. CCE, fines del siglo XVIII- principios del siglo XIX). 


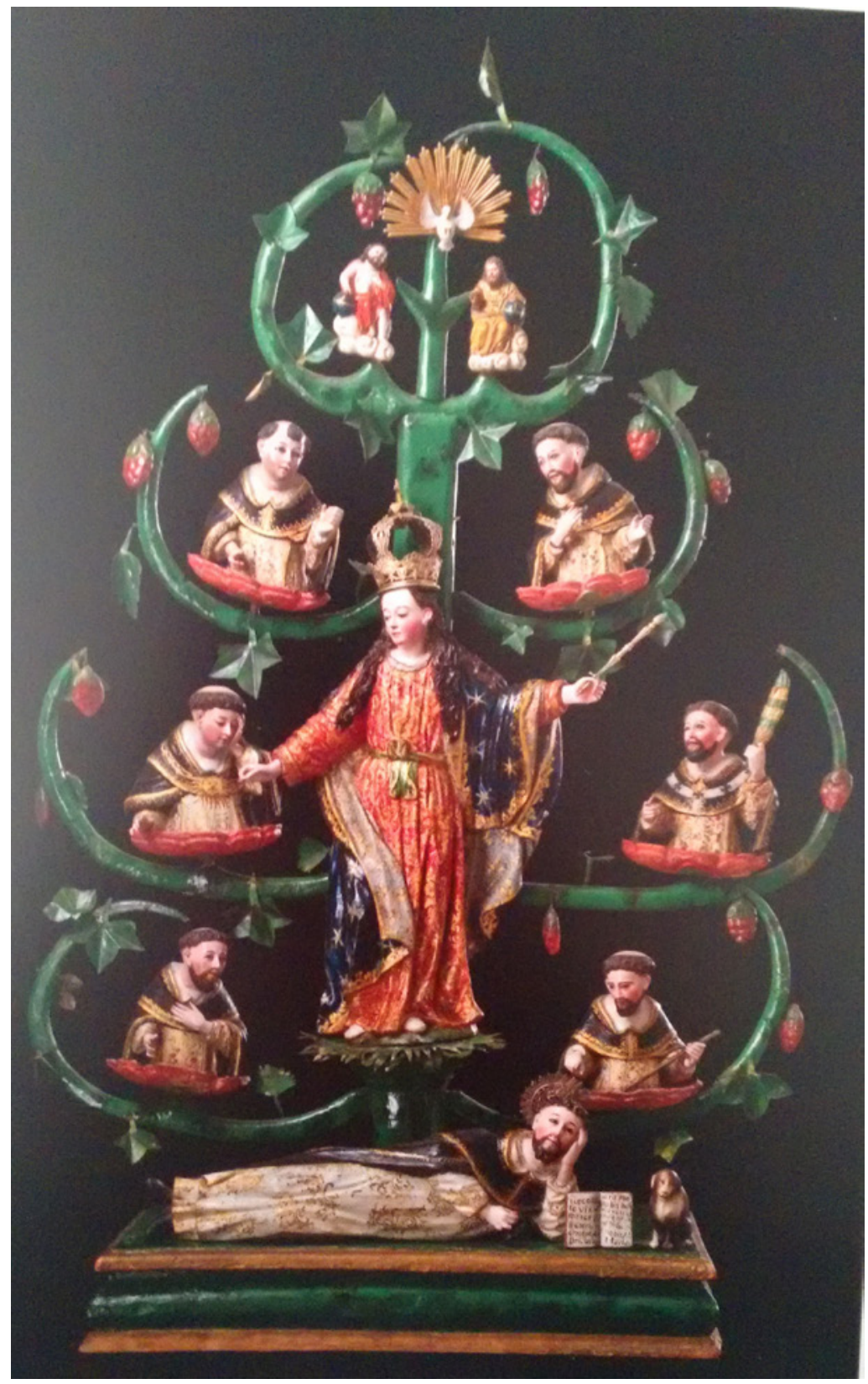

Figura 3. Anónimo. Virgen de la Escalera (Monasterio de Santa Catalina. Museo, siglo XVIII). 


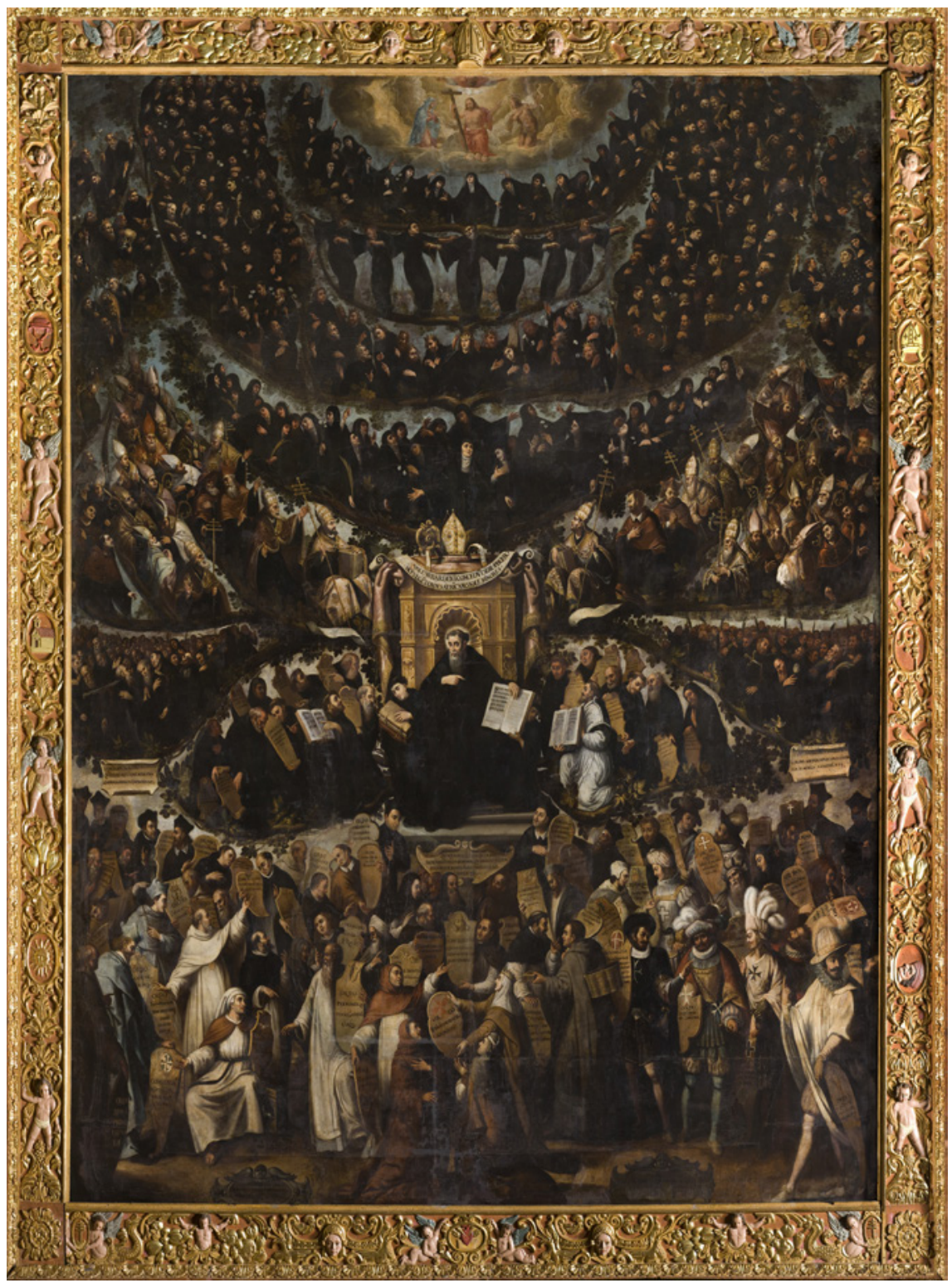

Figura 4. Miguel de Santiago y obrador. La Regla de San Agustín (Iglesia de San Agustín, Quito, 1656-58).

LABORATORIO DE ARTE 28 (2016), pp. 259-281, ISSN 1130-5762

e-ISSN 2253-8305 - DOI http://dx.doi.org/10.12795/LA.2006.i.01.14 


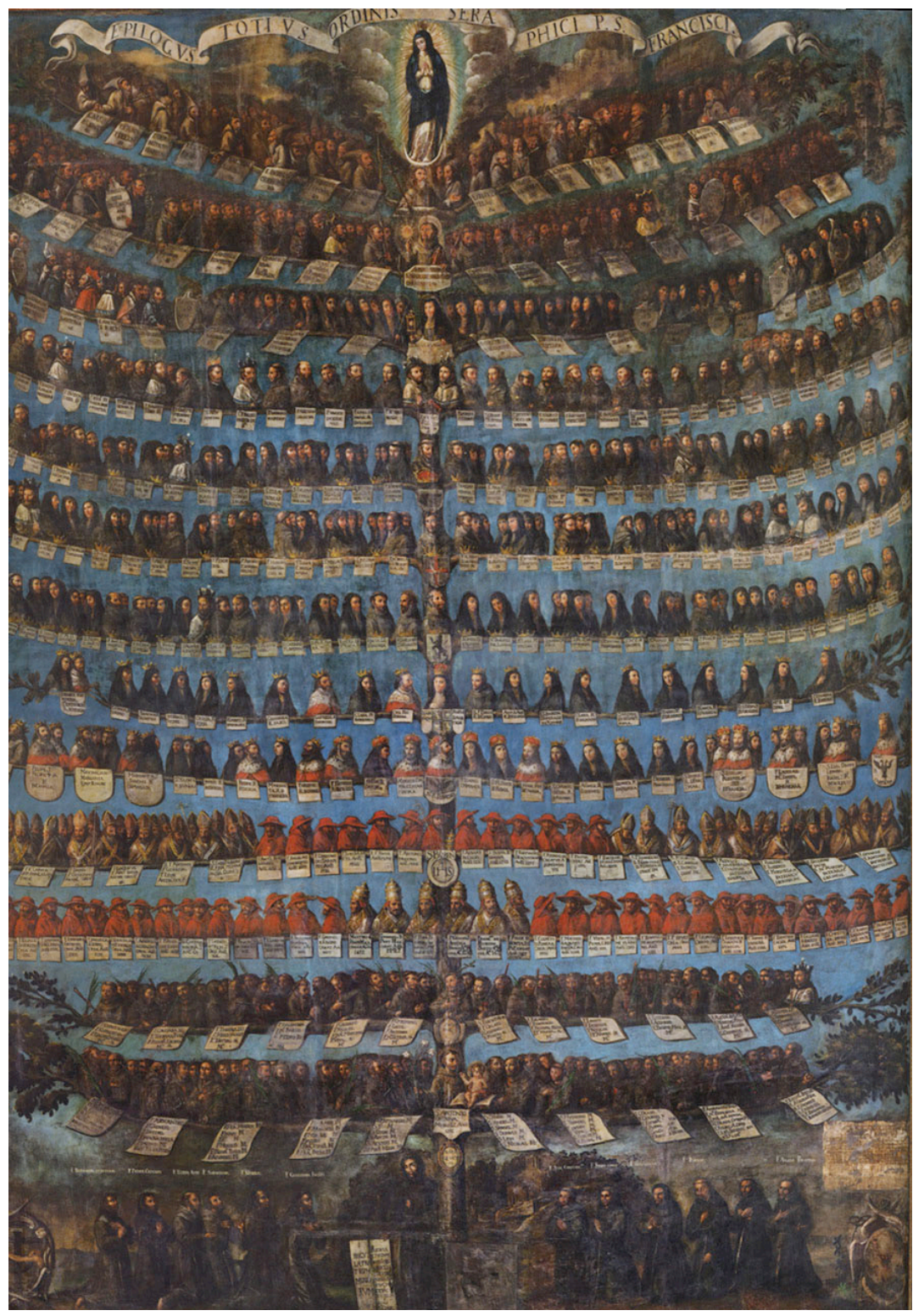

Figura 5. Anónimo. Árbol genealógico franciscano (Convento de San Francisco de Quito, mediados del siglo XVII). 


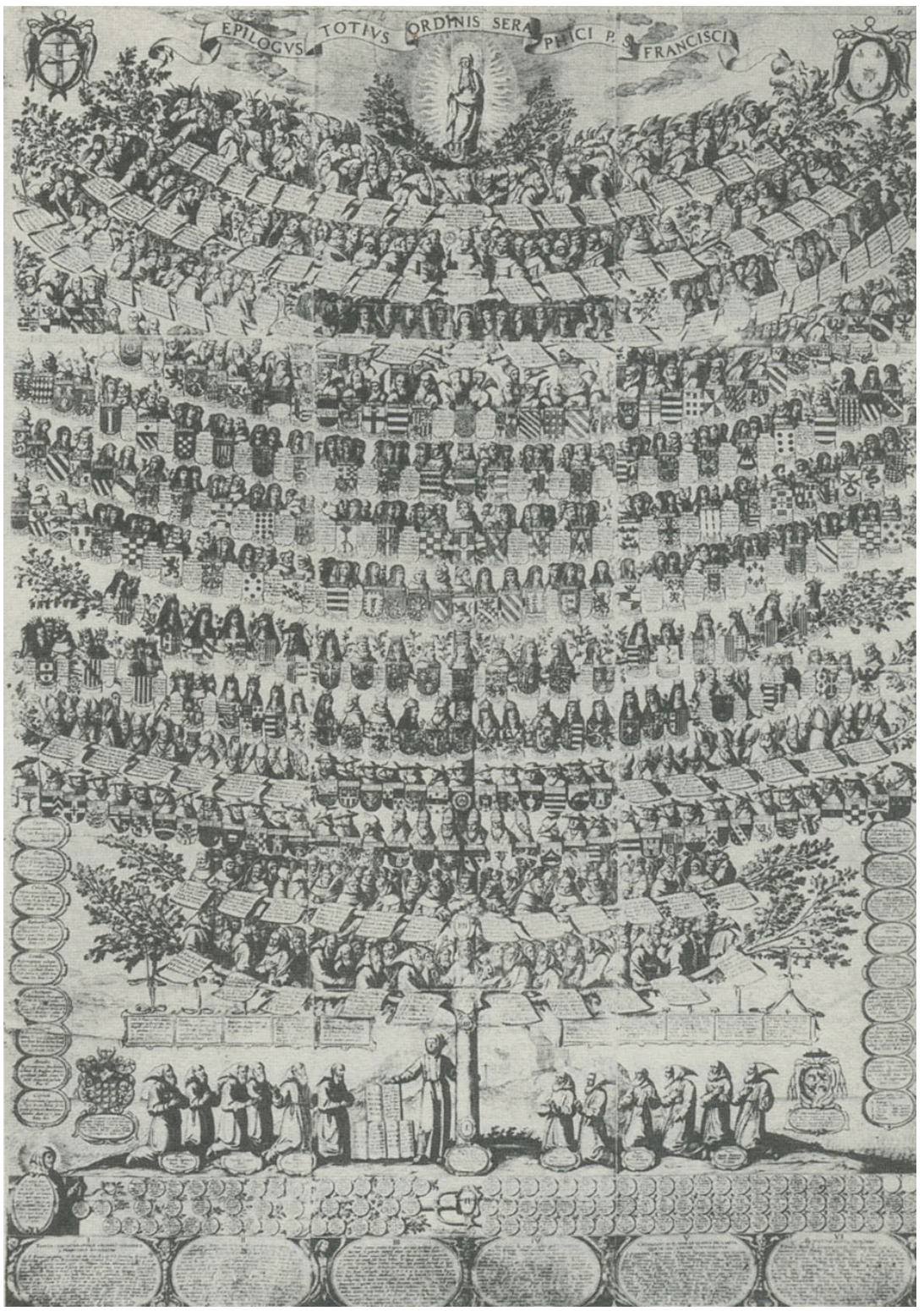

Figura 6. Grabado de Peeter de Jode I, modelo para el árbol franciscano anterior. 


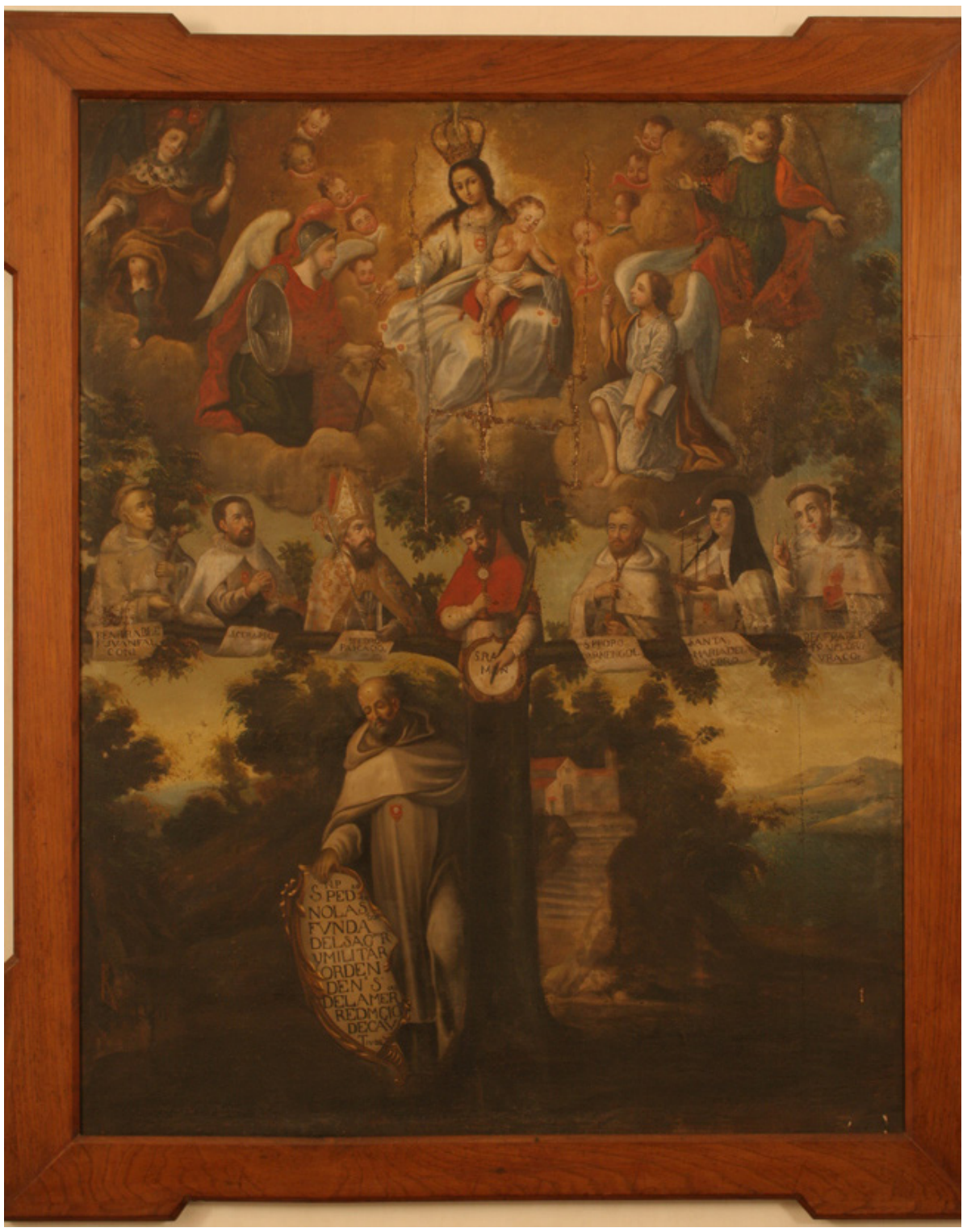

Figura 7. Anónimo. Árbol genealógico de la orden mercedaria (Recoleta de El Tejar, Quito, ha. tercer cuarto del siglo XVIII).

LABORATORIO DE ARTE 28 (2016), pp. 259-281, ISSN 1130-5762 e-ISSN 2253-8305 - DOI http://dx.doi.org/10.12795/LA.2006.i.01.14 